\title{
OP56
}

\section{REVISION OF THE INTERNATIONAL STANDARDS OF LIGHTING OF INTERIOR WORKPLACES

\author{
Peter Dehoff
}

DOI 10.25039/x46.2019.OP56

from

CIE x046:2019

\author{
Proceedings \\ of the \\ 29th CIE SESSION \\ Washington D.C., USA, June 14 - 22, 2019 \\ (DOI 10.25039/x46.2019)
}

The paper has been presented at the 29th CIE Session, Washington D.C., USA, June 14-22, 2019. It has not been peer-reviewed by CIE.

\section{(C) CIE 2019}

All rights reserved. Unless otherwise specified, no part of this publication may be reproduced or utilized in any form or by any means, electronic or mechanical, including photocopying and microfilm, without permission in writing from CIE Central Bureau at the address below. Any mention of organizations or products does not imply endorsement by the CIE.

This paper is made available open access for individual use. However, in all other cases all rights are reserved unless explicit permission is sought from and given by the CIE.

CIE Central Bureau

Babenbergerstrasse 9

A-1010 Vienna

Austria

Tel.: +43 17143187

e-mail: ciecb@cie.co.at

www.cie.co.at 


\title{
REVISION OF THE INTERNATIONAL STANDARDS OF LIGHTING OF INTERIOR WORKPLACES
}

\author{
Peter Dehoff \\ Zumtobel Lighting GmbH, Schweizer Straße 30, 6850 Dornbirn, AUSTRIA \\ peter.dehoff@zumtobelgroup.com
}

DOI $10.25039 / \times 46.2019 .0 P 56$

This contribution is dedicated to Mr Lou Bedocs who passed away in March 2019. Lou was a long serving member of CEN TC 169 WG2, was heavily involved in the revision of this draft and formerly the convenor of ISO/TC 159/SC 5.

\begin{abstract}
Two important international standards have started the process of revision: one is the ISO 8995/ CIE S 008 "Lighting of indoor workplaces" (2001/2002) which was prepared by ISO/TC 159/SC 5 and CIE TC 3-21 and the other is EN 12464-1 "Lighting of indoor workplaces" (2011). Requirements in light and lighting technology have changed considerably since the initial drafts of these standards. The focus is very much on the comfort and well-being of people at work while respecting the energy efficiency of the lighting installation. Visual quality is the most important impact. But all effects of lighting have to be taken into account, as well as the increasing application of lighting management.
\end{abstract}

The revision of EN 12464 has been completed. It should be out for public enquiry shortly after the CIE session on July $18^{\text {th }}, 2019$.

CIE and ISO will start their revision in the ISO CIE JWG 5 directly at and after the CIE session.

Keywords: lighting standard, EN 12464, ISO 8995, lighting quality, lighting criteria, lighting design

\section{The importance of lighting standards for work places}

Developed and developing economies rely on the workforce of their people. Lighting of workplaces is of utmost importance to their economic success. Furthermore good lighting quality increases the ability of people to fulfil their work in the best way. Lighting standards for work places have a long history.

Good lighting practise as well as research on the effects of lighting on people provide input for our work on these lighting standards. They need to be balanced between available technology, quality for human and economic and ecological feasibility.

Lighting standards for the user workplaces were started in the early $20^{\text {th }}$ century including first CIE reports. The first European standard EN 12464-1 was published in 2002 followed by CIE S008/ISO 8995 also in 2002.

\section{Revision of European Standard EN 12464-1}

The revision of the second edition of EN 12464-1, published 2011, started in 2015. On the one hand there was a request to introduce the upcoming impact of non-visual effects of lighting, on the other hand the five year systematic review was initiated by CEN TC 169. 96 comments were received. These and the expertise of the members of WG 2 which is responsible for revising the standard made it a procedure of more than 15 two day meetings to conclude the draft for enquiry, by the beginning of 2019 .

It is important to mention that during the intensive work three aspects were key: 
1. Well established and known criteria shall be kept

2. Improvements according to new and accepted lighting knowledge and technology shall be incorporated

3. The standard shall be improved in its legibility

The content of the standard is given in chapter 3.

The structure and the general content was kept and further developed. The known parts are not repeated in this paper. It is mainly focused on those terms, parameters and chapters which were discussed in more detail and revised by the working group.

\subsection{Confirming lighting criteria}

From the beginning EN 12464-1 focussed on requirements for good lighting solutions. It was never intended to be a design guide. However, lighting design criteria and lighting design considerations form two major chapters of the standard. The latter is new (see 2.4 below).

Good lighting practice starts with creating a proper luminous environment to satisfy the basic human needs for visual comfort, visual performance and safety. The parameters used in the standard to describe this are luminance distribution, illuminance, directionality, variability, colour rendering, colour appearance and glare.

It was a clear target during the revision to confirm those parameters which are already well established.

\subsubsection{Task areas}

The visual task has to be fulfilled on task areas. These can be areas with one visual task or areas with more than one visual task which is then an activity area. Room areas are activity areas which cover the entire room or a significant part of a large room.

A new figure is introduced in the standard. It shows that the task area may be horizontal, vertical or inclined and is encircled by the immediate surrounding. Around that is the background area, usually at floor level.

b)

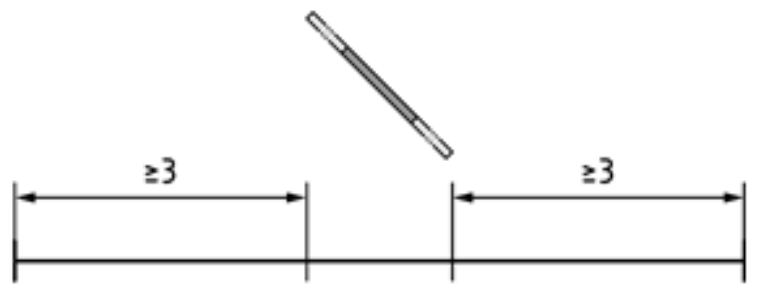

Figure 1 - fragment from EN 12464-1 for inclined task area with immediate surrounding area and background area on floor level

\subsubsection{Maintained illuminance}

The maintained illuminance $\bar{E}_{m}$ is the most well-known parameter as it specifies the light level at a workplace to fulfil the visual task. This value was kept in the standard as the minimum required light level. It was always understood that higher light levels should be achieved for a better performance of the visual task. There are also good reasons to increase the illuminance, e.g. if the work is critical, errors are costly, accuracy, higher productivity or increased concentration is of great importance, task details are of unusually small size, the task or activity area has a low daylight provision or if the visual capacity of the worker is below normal which is the case for elderly workers. 
- Beside the (old) maintained illuminance $\bar{E}_{m, r}$ a second (new) value $\bar{E}_{m, u}$ is introduced to give attention to the possibility to choose the maintained illuminance for a lighting installation in this band between the minimum and an upper value

See the examples in 2.4

\subsubsection{Glare}

Unified glare rating is the commonly used method for evaluating glare

- The formula is removed from the standard but is still the basis for UGR evaluation. To select a luminaire the tabular method shall be used to check against the limiting UGR value RugL.

The term for the limiting value is now $R_{U G L}$ instead of $U G R_{L}$. This is due to new regulations by CEN on how to use terms.

Daylight glare probability (DGP) is introduced with reference to the new daylight standard EN 17037.

Shielding angles are supplemented by requirements of covered light sources as these are very often LED.

A new annex B gives some "Recommended practice regarding implementation of UGR for 'nonstandard' situations".

\subsubsection{Cylindrical illuminance}

A well-lit interior space is of major importance for the acceptance of a room and the recognition of objects and people within this room. Illuminances on vertical areas, modelling and directionality of light are parameters to describe this.

- The requirement for cylindrical illuminance $\bar{E}_{z}$ is moved to tables 6 for higher awareness

\subsubsection{Room surface illuminances}

Room brightness is achieved by bright room surfaces and has an important impact on the wellbeing and visual comfort of people in interiors. Minimum values were in the existing standards.

- Minimum illuminances for walls $\bar{E}_{\mathrm{m} \text {,wall }}$ and ceiling $\bar{E}_{\mathrm{m}, \text { ceiling }}$ were moved from the main text to the tables 6 for higher awareness

The values for room brightness were general values in the main text in chapter 4.2.3 of the existing standard. In tables 6 they are now much better adapted to the rooms in which the visual tasks are carried out. The reason is well explained in annex $C$ of the new draft standard which highlights the need for perceived room brightness giving "Additional information on visual and non-visual (non-image forming) effects of light".

\subsubsection{Uniformity and Colour rendering}

- Uniformity $U_{o}$ on task or activity areas and colour rendering $R_{a}$ stay as before

The parameters for design criteria mentioned in this paragraph are captured from the existing standard as they are well accepted in practise. Only in specific cases, or when comments were given during the systematic review, some adaptions were incorporated.

\subsection{Next steps in the standard development}

Human and user needs are given a broader acknowledgement in the revision of the standard. Furthermore in technology LED has taken over from conventional lamps as the dominant light source.

The broader reflection of user needs are always taken into account when revising and improving the main text of the standard. For example the band of illuminances (see 2.1.2) allows a much 
more individual choice of illuminance levels and inspires the variability of light (see 3.). The impact of visual and non-image forming effects of light are elaborated in the new Annex C. Flicker and stroboscopic effects are an issue even if exact metrics and limiting values are not available as good practise recommendations at this time.

\subsection{Enhance lighting design}

A new chapter 5 "Lighting design considerations" is introduced with the additional aspects of recommended illuminance requirements, operation of the lighting system, energy efficiency requirements and variability of light.

The steps on how to choose the appropriate parameters from tables 6 are explained.

- First the parameters for "lighting of the task or activity area and its immediate surrounding area" shall be determined.

- Secondly the tasks, one or more, which have to be fulfilled within a space must be considered. The parameters for "lighting the space" shall be determined.

Lighting should be adjustable. Operation of the lighting system using lighting controls is an essential quality of a lighting system and should be fully considered during design, installation and commissioning.

Maintenance shall be considered.

See 2.4 and 3 "content" for the details of the table and the design considerations.

\subsection{Revised table 6 of lighting requirements}

The core of the standard is table 6 . The requirements are visible here at a glance.

"The requirements for the specific tasks and activities are given by $\bar{E}_{\mathrm{m}, \mathrm{r}}, \bar{E}_{\mathrm{m}, \mathrm{u}}, U_{\mathrm{o}}, \mathrm{R}_{\mathrm{a}}$ and $R \cup \mathrm{ug}$. The requirements for the space in which the task(s) or activities are carried out are given by $E_{z}$ for the perception of objects and people within this space and $\bar{E}_{\mathrm{m} \text {,wall }}$ and $\bar{E}_{\mathrm{m} \text {,ceiling }}$ for room brightness. The latter are used for designing the room and the space including RuGL. Glare (by $R_{U G L}$ ) is related to the space in which a task is carried out. The first four columns are used for task or activity area design and more than one of these areas may occur within one space.

This applies to columns 3 to 10 in all tables in 6.3."

Table 6.0 - Assignment of columns to requirements

\begin{tabular}{|c|c|c|c|c|c|c|c|}
\hline \multicolumn{4}{|c|}{$\begin{array}{c}\text { Task or activity area } \\
\text { design }\end{array}$} & \multicolumn{4}{|c|}{ Room or space design } \\
\hline \multicolumn{5}{|c|}{$\begin{array}{l}\text { Task or activity related } \\
\text { requirements }\end{array}$} & $\begin{array}{l}\text { Importance } \\
\text { of objects } \\
\text { and people }\end{array}$ & $\begin{array}{r}\text { Brig } \\
\text { appea } \\
\text { rc } \\
(4.2 .\end{array}$ & $\begin{array}{l}\text { thess } \\
\text { rance of } \\
\text { oms } \\
/ 4.2 .3)\end{array}$ \\
\hline $\begin{array}{l}\bar{E}_{\mathrm{m}, \mathrm{r}} \\
\mathrm{Ix}\end{array}$ & $\begin{array}{l}\bar{E}_{\mathrm{m}, \mathrm{u}} \\
\mathrm{Ix}\end{array}$ & $U_{\mathrm{o}}$ & $\mathrm{R}_{\mathrm{a}}$ & RUGL & $\begin{array}{l}\overline{E_{z}} \\
\mathrm{Ix}\end{array}$ & $\underset{\mathrm{Ix}}{\bar{E}_{\mathrm{m}, \text { wall }}}$ & $\begin{array}{c}\bar{E}_{\mathrm{m}, \text { ceiling }} \\
\mathrm{Ix}\end{array}$ \\
\hline
\end{tabular}

This introduction is followed by tables 6.1 to 6.54 .

Table 6.26 Offices may serve as an example. 
Table 6.26 - Offices

\begin{tabular}{|c|c|c|c|c|c|c|c|c|c|c|}
\hline Ref. no. & $\begin{array}{l}\text { Type of } \\
\text { task/activity area }\end{array}$ & $\begin{array}{l}\bar{E}_{\mathrm{m}, \mathrm{r}} \\
\mathrm{Ix}\end{array}$ & $\begin{array}{l}\bar{E}_{\mathrm{m}, \mathrm{u}} \\
\mathrm{Ix}\end{array}$ & $U_{0}$ & $R_{\mathrm{a}}$ & $R_{\mathrm{UGL}}$ & $\begin{array}{l}\bar{E}_{\mathrm{z}} \\
\mathrm{Ix}\end{array}$ & $\begin{array}{l}\bar{E}_{\mathrm{m}, \text { wall }} \\
\mathrm{Ix}\end{array}$ & $\begin{array}{l}\bar{E}_{\mathrm{m}, \text { ceiling }} \\
\mathrm{Ix}\end{array}$ & $\begin{array}{l}\text { Specific } \\
\text { requirements }\end{array}$ \\
\hline 6.26 .1 & $\begin{array}{l}\text { Filing, copying, } \\
\text { etc. }\end{array}$ & 300 & 500 & 0,40 & 80 & 19 & 100 & 100 & 75 & \\
\hline 6.26 .2 & $\begin{array}{l}\text { Writing, } \\
\text { reading, } \\
\text { processing }\end{array}$ & 500 & 1000 & 0,60 & 80 & 19 & 150 & 150 & 100 & $\begin{array}{l}\text { DSE-work, } \\
\text { see } 4.9 . \text { see } \\
5.7 \quad \text { room } \\
\text { brightness }\end{array}$ \\
\hline 6.26 .3 & Technical drawing & 750 & 1500 & 0,70 & 80 & 16 & 150 & 150 & 100 & $\begin{array}{l}\text { DSE-work, } \\
\text { see } 4.9 . \text { see } \\
5.7 \quad \text { room } \\
\text { brightness }\end{array}$ \\
\hline 6.26 .4 & CAD work stations & 500 & 1000 & 0,60 & 80 & 19 & 150 & 150 & 100 & $\begin{array}{l}\text { DSE-work, } \\
\text { see } 4.9 \text {. }\end{array}$ \\
\hline 6.26 .5 .1 & $\begin{array}{l}\text { Conference and } \\
\text { meeting rooms }\end{array}$ & 500 & 1000 & 0,60 & 80 & 19 & 150 & 150 & 100 & $\begin{array}{l}\text { Lighting } \\
\text { should be } \\
\text { controllable. }\end{array}$ \\
\hline 6.26 .5 .2 & Conference table & 500 & 1000 & 0,60 & 80 & 19 & 150 & 150 & 100 & $\begin{array}{l}\text { Lighting } \\
\text { should be } \\
\text { controllable. }\end{array}$ \\
\hline 6.26 .6 & Reception desk & 300 & 750 & 0,60 & 80 & 22 & 100 & 100 & 75 & \\
\hline 6.26 .7 & Archiving & 200 & 300 & 0,40 & 80 & 25 & 75 & 75 & 50 & \\
\hline
\end{tabular}

\section{Content of prEN 12464-1}

A provisional content of the draft standard is as follows:

European foreword

Introduction

1 Scope

2 Normative references

3 Terms and definitions

4 Lighting design criteria.

4.1 Luminous environment

4.2 Luminance distribution

4.2.1 General

4.2.2 Reflectance of surfaces

4.2.3 Iluminance on surfaces

4.3 Illuminance

4.3.1 General

4.3.2 Scale of illuminance

4.3.3 Illuminances on the task or activity area

4.3.4 Illuminance on the immediate surrounding area 
4.3.5 Illuminance on the background area

4.3.6 Illuminance uniformity

4.4 Illuminance grid

4.5 Glare.

4.5.1 General

4.5.2 Discomfort glare

4.5.3 Shielding against glare

4.5.4 Veiling reflections and reflected glare

4.6 Lighting in the interior space

4.6.1 General

4.6.2 Mean cylindrical illuminance requirement in the activity space

4.6.3 Modelling

4.6.4 Directional lighting of visual tasks.

4.7 Colour aspects

4.7.1 General

4.7.2 Colour appearance

4.7.3 Colour rendering

4.8 Flicker and stroboscopic effects

4.8.1 General

4.8.2 Flicker

4.8.3 Stroboscopic effect

4.9 Lighting of work stations with Display Screen Equipment (DSE)

4.9.1 General

4.9.2 Luminaire luminance limits with downward flux

5 Lighting design considerations

5.1 General

5.2 Illuminance requirements and recommendations

5.2.1 Lighting of the task or activity area and its immediate surrounding area (see 4.3.1)

5.2.2 Lighting of the space

5.2.3 Operation of the lighting system

5.3 Maintenance factor

5.4 Energy efficiency requirements

5.5 Additional benefits of daylight

5.6 Variability of light.

5.7 Room brightness

6 Schedule of lighting requirements

6.1 Composition of the tables

6.2 Schedule of interior areas, tasks and activities

6.3 Lighting requirements for task and activity areas

7 Verification procedures

7.1 General

7.2 Illuminances....

7.3 Unified Glare Rating

7.4 Colour rendering and colour appearance

7.5 Luminaire luminance

7.6 Maintenance schedule

Annex A (informative) Typical values of grid point spacing 
Annex B (informative) Recommended practice regarding implementation of UGR for 'non-standard' situations....

B.1 General

B.2 Recommended Practices

B.2.1 Deviating Luminaire sizes

B.2.2 Irregular area shapes

B.2.3 Irregular luminaire placement patterns

B.2.4 Deviating room reflectance values

B.2.5 Multiple luminaire types

B.2.6 Luminaires with (only) up-lighting or luminous ceilings

B.2.7 Room dimensions smaller or larger than the tabular values

Annex C (informative) Additional information on visual and non-visual (non-image forming) effects of light.

C.1 General

C.1.1 Perceived room brightness

C.1.2 Alternative parameters

C.1.3 Adaptation luminance within the normal field of view.

C.1.4 The influence of spectral power distribution on non-image forming effects.

C.1.5 Varying lighting conditions

C.1.6 Daylight penetration

Annex D (informative) Lighting design considerations - Examples

Bibliography

Index

\section{Start of revision of ISO 8995-1}

The joint standard CIE S 008/ISO 8995-1 was published in 2002. During its meeting in Toronto 2018 ISO TC 274 established a JWG 5 between ISO and CIE to revise this standard. Beside the revision of the European standard other national and regional standards will also be taken into account.

\section{Concluding remark and recognition}

The revision of the European standard acknowledges the human and user needs and focusses on lighting quality by respecting new technologies and energy requirements. This is an essential contribution to the quality of life and to economic and ecological development.

The author expresses his deepest gratitude to the colleagues in working group 2 and the officers from DIN who helped with great endurance to finalise the draft standard in time. I hope that we can maintain this momentum for the final version. Furthermore I hope that ISO and CIE experts will passionately contribute to the ISO standard as well.

\section{References}

ISO 8995-1 (2002): Lighting of indoor work places (CIE S008/2001)

EN 12464-1 (2002) and (2011): Lighting of work places - Indoor work places 